\title{
The role of the specialty training committee
}

\author{
Ian N Scobie
}

\begin{abstract}
Many medical (and other) trainees will have heard mention during their training years of the specialty training committee (STC) relevant to their chosen medical specialty and might even be aware of some of the trainer members who sit on this committee. However, there is a perception that, equally, many trainees have no clear understanding of the roles and functions of STCs in relation to their training and, furthermore, the relation of their STC to its local deanery. This might also extend to consultant educational trainers who are less involved in the broader provision of postgraduate medical training (although, ideally this should not be the case). Here, I provide a brief guide to the role of STCs in training and their relation to their local deanery.
\end{abstract}

\section{Definition of a specialty training committee}

That trainees might be confused as to what their specialty training committee (STC) actually does might not be surprising when one seeks to find a comprehensive definition of an STC. The Gold Guide 2010 (A reference guide for postgraduate specialty training in the $U K)^{1}$ defines an STC as 'the usual (but not the only name) used for the committee which advises and manages training in a specialty within a Postgraduate Deanery', whereas the Joint Royal Colleges of Physicians Training Board (JRCPTB) website defines an STC as 'a committee of the postgraduate

\footnotetext{
Ian N Scobie, consultant endocrinologist $1,2,3,4,5$

${ }^{1}$ Medway NHS Foundation Trust; ${ }^{2}$ Chair, Pan-London Specialist Training Committee in Endocrinology and Diabetes, London Deanery, 2010-2012; ${ }^{3}$ Co-chair, Pan-London Specialist Training Committee in General (Internal) Medicine, London Deanery; ${ }^{4}$ Training Programme Director, Specialist Training Programme in Endocrinology and Diabetes, Kent Surrey and Sussex Deanery; ${ }^{5}$ Member, Specialist Advisory Committee in Endocrinology and Diabetes, Joint Royal Colleges of Physicians Training Board
}

dean which has delegated to it many of the dean's duties for the specialty in question'. STCs have terms of reference that include where they get their authority from. They also feed into the Board of the School of Medicine. The London Deanery has embarked upon a new model for the provision of specialist training (which differs from that of other deaneries), whereby lead providers now manage training across sectors of London and, in future, STCs will become committees of lead providers rather than the London Deanery itself. STCs remain completely responsible for the management and quality assurance of training within a specialty.

\section{Constituent members of an STC}

Constituent members of an STC would normally include the STC chair, training programme director(s) (TPDs), head of school of medicine, associate dean, trainee representative, deanery medical workforce officer and training leads for individual Trusts or local education providers. Depending on the number of hospital training departments offering posts to a programme, STCs would normally seek a representative from each department within the geographical jurisdiction of that STC, plus an academic representative. This can vary from one deanery to another. For example, in the case of the large London Deanery, member representation of some large specialty STCs is confined to sector training programme directors only (otherwise, the committee would be too unwieldy to be effective.)

\section{Roles and functions of an STC}

The essential role of an STC, delivered through the key role of the STC chair assisted by the $\operatorname{TPD}(\mathrm{s})$, is to manage and develop the specialist training programme of the individual specialty and to ensure the delivery of the highest standard of training. The STC needs to ensure that the training programme meets the requirements of the Reference Guide for Postgraduate Specialty Training 
in the UK (The Gold Guide) ${ }^{1}$ and ensure coverage of the training curriculum as determined by the appropriate Royal College.

\section{Administration and management}

STCs must identify appropriate training placements and ensure that trainees are only placed in posts that have educational approval, that are appropriate for the level of training of the individual trainee and, where possible, meet their geographical needs. STC members lead and participate in the annual review processes (ie Record of In-Training Assessment (RITA) and Annual Review of Competence Progression (ARCP)) so that the progress of the individual trainees can be assessed and their further educational and training needs planned. STCs need to guarantee the interests of less than full time (LTFT) trainees, trainees in academic medicine and trainees who are out of programme in a period of full-time research, training, experience or career break, and also those doctors who are in a locum appointment for training (LAT) post.

\section{Delivery of training}

The STC chair, in collaboration with the TPD(s), provides leadership on the actual delivery of training within the training programme to comply with the standards set by the General Medical Council, Royal College of the relevant specialty and local deanery. This entails the establishment, with the involvement of STC members, of an appropriate training programme that can deliver the curricular requirements mandated by the JRCPTB. STCs usually appoint a flexible training lead who has the experience and expertise to lead on issues related to LTFT trainees and who assists in the coordination of an appropriate training programme for such trainees. Assessment of the individual training needs of trainees is undertaken at the annual ARCP-RITAs, which review the evidence of the curricular progress of trainees. Evidence is largely obtained from educational supervisors' reports and the trainees' electronic portfolio. Targets for the post experience will have been agreed previously. The RITA-ARCP panel issues a satisfactory outcome or describes the nature of the remediation required. Outcomes are described in The Gold Guide. ${ }^{1}$ In the thankfully uncommon situation whereby a trainee is judged to need targeted or remedial training at ARCP-RITA, the STC chair, TPD and other senior members of the STC agree on an appropriate placement to allow such activity to occur. Advice about the appropriateness of time spent out of programme (OOP experience (OOPE), training (OOPT), research (OOPR), etc) and how to achieve this, is usually discussed by trainees with the STC chair, TPD or academic representative (or a combination thereof). The STC chair, TPD or other members will offer counselling to trainees experiencing difficulties of a professional or personal nature when required and when the local college tutor, clinical tutor or clinical or educational supervisor is unable or inappropriate to fulfil this function. STCs advise on the appropriateness of interdeanery transfers (IDTs) and acceptance of incoming or outgoing trainees according to the recommendations laid down by The Gold Guide. Deaneries might have formed a specific committee to undertake this function.

\section{Monitoring and inspection}

STCs have a duty to monitor their training programme to ensure that it is continuing to provide training to the standards set out above. The deanery, through the postgraduate dean, will seek advice from an STC when bids are sought for a new training post within their training programme. STCs, which usually have one member who sits on the specialist advisory committee of the JRCPTB, can advise the deanery of the implications of proposed implementation of local increases or decreases in numbers of trainees and/or posts in line with national allocations and information from the Centre for Workforce Intelligence (CfWI).

STCs have a duty of responsibility to address local training issues that might be triggered by the concerns of trainees or their trainers. If these are of sufficient seriousness, then the STC chair should escalate the issue to the head of school, associate dean and/or college regional specialty advisor. Most STCs can refer trainees needing extra support to their trainee support and/or in-difficulty group for review and planning of required interventions or remedial targets. Trust issues might necessitate involvement of the director of medical education and/or clinical tutor, college tutor or clinical director. Many STC members lead or take part in visiting teams to other local educational providers that deliver the specialty curriculum. Most STCs also conduct their own specific trainee surveys. Trainee representatives have a key role within STCs, delivering a trainee representative report at each STC meeting that allows trainees within the programme to feedback concerns directly to the STC, as well as to contribute to the organisation of training days with particular regard to curriculum mapping. Trainee representatives are encouraged to develop innovative ideas that can be incorporated into the training programme.

Each year, the STC contributes to the annual specialty report of the school of medicine describing key activities within the training programme, including a response to the annual General Medical Council (GMC) trainee and trainer surveys, with particular emphasis on posts that receive adverse comments and on the deanery quality management requirements. This is in addition to any reports required by the head of school or associate and/or postgraduate dean in connection with issues such as curriculum mapping, specialty risk registers and so on. The annual specialty report in turn enables the school of medicine to report to the JRCPTB and national specialty reports are forwarded to the regulator. The business plan of an STC will feed into the overall school of medicine business plan.

\section{Recruitment to the specialty}

STC members, usually through the STC chair or TPD, are involved in the approval of the wording of advertisements for 
recruitment to the specialty in the knowledge of the person specification and specialty training prospectus and, in the case of new posts, help validate and obtain educational approval for such posts. They are also closely involved in the short-listing and interview process, and will be responsible for allocating the successful candidates to the vacant placements within the training programme that are appropriate to the training needs of the new appointees.

\section{Conclusion}

Thus, it should be apparent that, even if it is not widely recognised, STCs perform complex but crucial functions on behalf of their local deanery. It must be emphasised that STCs might differ in how they carry out their responsibilities from locality to locality, but their broad role is as described above. It can be seen that the activities of the STC are widespread, although fundamental to their role is the welfare of their trainees in the broadest sense and the assurance of the quality of training in the programme for which they bear responsibility.

\section{Acknowledgements}

Many thanks to Kevin Kelleher, Jeremy Levy and John Quin.

\section{Reference}

1 NHS. A reference guide for postgraduate specialty training in the UK (The Gold Guide 2010). NHS, 2010. www.mmc.nhs.uk/pdf/Gold\%20 Guide $\%$

202010\%20Fourth\%20Edition\%20v08.pdf [Accessed 28 May 2012].

Address for correspondence: Dr Ian N Scobie, Diabetes Centre, Medway Maritime Hospital, Gillingham, Kent ME7 5NY.

Email: ian.scobie@kcl.ac.uk

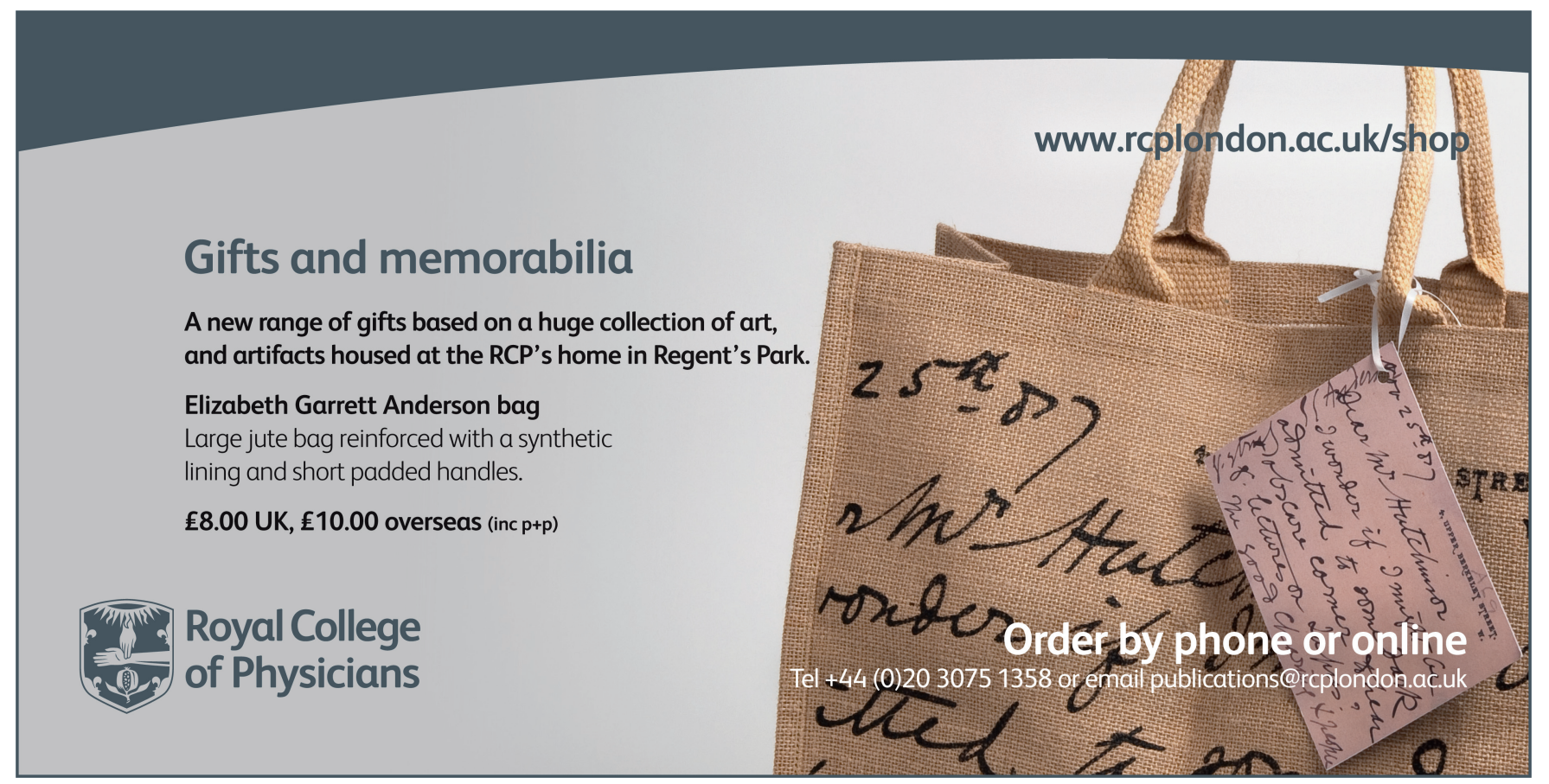

